\title{
PEDAGOGIA DO ESPORTE E A APLICAÇÃO DAS TEORIAS ACERCA DOS JOGOS ESPORTIVOS COLETIVOS EM ESCOLAS DE ESPORTES: O CASO DE UM CLUBE PRIVADO DE CAMPINAS - SP
}

Larissa Rafaela Galatti

Roberto Rodrigues Paes

\section{Resumo}

O presente artigo apresenta uma proposta de iniciação esportiva aplicada em um clube privado na cidade de Campinas, cujo objetivo foi o de promover a iniciação com a diversificação de modalidades, tendo o foco nos Jogos Esportivos Coletivos (JEC), a partir das teorias propostas por autores europeus. A proposta foi aplicada no Tênis Clube de Campinas (TCC) entre junho de 2004 e julho de 2005 com crianças entre 4 e 12 anos, em 3 diferentes turmas, todas compostas por meninos e meninas. As práticas partiram da noção de características comuns aos JEC propostos pelo autor francês Claude Bayer (1994), assim como das idéias de princípios operacionais de defesa e ataque e de regras de ação, propostas pelo mesmo autor. Outros três pressupostos tidos como fundamentais na estruturação das práticas, foram a imprevisibilidade dos JEC e os estímulos à inteligência e a cooperação, traços considerados fundamentais aos jogadores de JEC pelo autor português Garganta (1995).

\section{Palavras-Chave}

Pedagogia do esporte; Jogos esportivos coletivos; Iniciação esportiva.

\section{SPORT PEDAGOGY AND THE APPLICATION OF THE THEORIES CONCERNING TO THE COLLECTIVE SPORTIVE GAMES IN SCHOOLS OF SPORTS: THE CASE OF A PRIVATE CLUB OF CAMPINAS - SP.}

Larissa Rafaela Galatti

Roberto Rodrigues Paes

\begin{abstract}
This paper presents a proposal on how to deal with initiation in sports, which was applied to a private social club in the city of Campinas. Our main goal was to provide a general motor initiation, considering many different sports, based on team games, written by European authors. We worked in Tênis Clube de Campinas (TCC), between June, 2004 and July, 2005, with children between 4 and 12 years old, divided into 3 different groups. The practices followed the main idea of the team games theory, the defense and offense principles and the action plans, written by Claude Bayer (1994). We also considered, during lesson planning, that team games are not predictable, and stimulate cooperation and intelligence development, as Garganta (1995), a Portuguese author wrote.
\end{abstract}

\section{Key-Words}

Pedagogy in sports; Team games, Sports initiation. 


\section{INTRODUÇÃO}

Considerando o Esporte como um fenômeno sócio-cultural de múltiplas possibilidades, este estudo tem por objetivo mostrar as contribuições das teorias propostas por autores europeus a partir do final da década de 1970 e do início da década de 1980 para a prática pedagógica com Jogos Esportivos Coletivos. Para tal, partiremos de uma retomada bibliográfica dos autores que mais influenciaram os autores brasileiros que lidam com o tema e complementaremos a possibilidade de aplicação destas teorias a partir do relato de um trabalho de iniciação esportiva diversificada realizada em um clube privado na cidade de Campinas/SP.

A partir da década de 1970 Europa e 1980/90 no Brasil, os Jogos Esportivos Coletivos (JEC) deixam de ser analisados à luz das teorias para modalidades individuais e passam a ser alvo de estudos específicos que levam em conta a coletividade e a imprevisibilidade. Entretanto, ao menos em nosso país, a mudança de paradigma se deu apenas nos estudos teóricos, ficando o processo de ensino e aprendizagem em JEC ainda carregada de práticas fragmentadas, pautadas na repetição de gestos e modelos oriundos de padrões do esporte-espetáculo.

Desta forma, as características fundamentais dos JEC - como a imprevisibilidade, cooperação e inteligência, destacados por Garganta (1995), ou a possibilidade de "transfer" ou transferência de conteúdos e aprendizagens entre os JEC a partir de suas características comuns, como apresenta Bayer (1994) ou ainda as possibilidades de intervenção no meio sócio-cultural a partir do esporte, como aborda Cagigal (1981), Paes (2001) e Balbino (2001), este último destacando o esporte como uma metáfora da vida - de uma forma geral, parecem ser desconsideradas no trato com os JEC tanto no esporte profissional, como no esporte no ambiente escolar e na iniciação esportiva não formal, sendo este contexto o foco principal deste estudo.

$\mathrm{Na}$ expectativa de contribuir para a mudança do trato com os JEC para além das linhas teóricas, este artigo é assim construído: inicialmente, o esporte é abordado a partir de sua concepção enquanto fenômeno sócio-cultural; a seguir, os jogos esportivos coletivos serão tratados a partir da revisão bibliográfica de autores europeus, expandindo para alguns nomes nacionais; na seqüência, serão discutidos os métodos de trabalho com os JEC; por fim, será descrita a proposta para a iniciação esportiva com foco em JEC elaborada a partir dos autores que serão contemplados neste estudo e que foi aplicada no Tênis Clube de Campinas. 


\section{O FENÔMENO ESPORTE}

De acordo com Tubino (1987), o Esporte Moderno, em sua forma institucionalizada, surge na Inglaterra no final do século XIX e início do século XX balizado em dois pilares complementares: o fornecimento do prazer para quem joga e para os espectadores, e a oportunidade da formação moral. O grande marco da configuração do Esporte Moderno foi a retomada dos Jogos Olímpicos e os ideais a ele ligados, pelo francês Pierre de Coubertin, que institui os Jogos Olímpicos da Era Moderna, internacionalizando o esporte a partir de ideais comuns; para tal, foi necessária também uma internacionalização das regras, massificando e aproximando o esporte, seus promotores, praticantes e espectadores por todo o mundo.

Atualmente, o Esporte vem sendo estudado, debatido, ensinado e se manifestado na sociedade de diversas maneiras, gerando também uma pluralidade de definições. Para se ter uma idéia do alcance e aceitação do esporte pelo mundo, como também de sua relevância na cultura dos povos, o Comitê Olímpico Internacional (COI), através do Movimento Olímpico, agrega 202 Comitês Olímpicos Nacionais. A ONU (Organização das Nações Unidas), órgão internacional de cunho político institucional, tem 200 filiados. É também um dos negócios mais rentáveis do mundo, gerando milhares de empregos e movimentando bilhões de dólares ao redor do planeta.

O Esporte, na atualidade, está presente em diversos segmentos da sociedade e da ciência, existindo hoje a medicina esportiva, a engenharia para ambientes e equipamentos esportivos, a computação e tecnologia a serviço do esporte, a estatística, a publicidade, propaganda e marketing, a economia, a sociologia do esporte, entre outros.

Betti (1991, p. 24), nos trouxe uma definição técnica de esporte:

O esporte tem sido conceituado como uma ação social institucionalizada, convencionalmente regrada, que se desenvolve com base lúdica, em forma de competição entre duas ou mais partes oponentes ou contra a natureza, cujo objetivo é, através de uma comparação de desempenhos, designar o vencedor ou registrar o recorde; seu resultado é determinado pela habilidade e estratégia do participante, e é para este gratificante tanto intrínseca como extrinsecamente.

Segundo Bento (1991, p. 17), a imagem atual de pluralidade do esporte nos dirige à sua caracterização como:

[...] um fenômeno sociocultural que representa, promove e disponibiliza formas muito distintas, mas todas especificamente socioculturais e historicamente datadas, de lidar com a corporalidade. 
Paes (1998, p. 112), por sua vez, assim descreveu o esporte:

O esporte é uma representação simbólica da vida, de natureza educacional, podendo promover no praticante modificações tanto na compreensão de valores como nos costumes e modo de comportamento, interferindo no desenvolvimento individual, aproximando pessoas que tem, neste fenômeno, um meio para estabelecer e manter um melhor relacionamento social.

Diante destas diferentes caracterizações, podemos analisar o esporte a partir de dois referenciais: o metodológico e o sócio-educativo. O referencial metodológico diz respeito aos seguintes temas:

- Métodos de ensino e aprendizagem;

- Planejamento ao longo do período (mês, bimestre, semestre, ano...);

- Organização de cada aula/treino;

- Adequação da proposta ao grupo de trabalho;

- Aspectos Técnicos;

- Aspectos Táticos;

- Aspectos Físicos.

O referencial sócio-educativo, por sua vez, relaciona-se aos seguintes objetivos:

- Promover a discussão de princípios, valores e modos de comportamento;

- Propor a troca de papéis (colocar-se no lugar do outro);

- Promover a participação, inclusão, diversificação, a co-educação e a autonomia;

- Construir um ambiente favorável para desenvolvimento de relações intra-pessoais e inter-pessoais (coletivas);

- Estabelecer relações entre o que acontece na aula de esportes com a vida em comunidade.

Observa-se, assim, a pluralidade de possibilidades de intervenção pelo esporte, seja a fim de difundir suas técnicas e modalidades ou com o intuito de promover e discutir valores. Assim, não nos parece mais possível concebermos uma iniciação esportiva pautada na repetição de gestos e na subordinação do esporte a treinadores que não consideram todas as suas possibilidades de intervenção, diminuindo consideravelmente as relações e interações que os alunos podem construir com os colegas, o próprio treinador e o esporte. Ao avançarmos para o foco deste artigo, os Jogos Esportivos Coletivos, ficarão ainda mais evidentes os dois referenciais de análise e intervenção do esporte, pelas próprias características dos JEC, como veremos a seguir. 


\section{JOGOS ESPORTIVOS COLETIVOS}

Os Jogos Esportivos Coletivos (JEC), como relata Bayer (1994), tem sua origem em antigas civilizações, séculos antes de Cristo, com alguns jogos semelhantes a muitas modalidades que se desenvolveram somente no século XX, como basquetebol, rugby e futebol. Buscando uma definição para Jogos Desportivos Coletivos, assim escreveu Teodorescu (1984, p. 23):

O Jogo Desportivo Coletivo representa uma forma de atividade social organizada, uma forma específica de manifestação e de prática, com caráter lúdico e processual, do exercício físico, na qual os participantes (jogadores) estão agrupados em duas equipes numa relação de adversidade típica não hostil (rivalidade desportiva) - relação determinada pela disputa através de luta com vista à obtenção da vitória desportiva, com a ajuda da bola (ou de outro objeto de jogo) manobrada de acordo com regras pré-estabelecidas.

Avançando no estudo dos JEC, o autor francês Claude Bayer (1994) nos mostra que todo esporte coletivo, por maior que sejam suas diferenças na execução técnico-tática, apresentam invariantes que lhes são comum, sendo elas:

- um objeto esférico a ser lançado pelo indivíduo com a mão, o pé ou com

o auxílio de um instrumento;

- um terreno demarcado de jogo, limite de ação de quem joga;

- um alvo a ser atacado ou defendido;

- os integrantes de uma equipe, que ajudam a progressão da bola com diferentes partes do corpo;

- adversários que devem ser vencidos;

- regras do jogo a serem respeitadas.

A partir destas características, o autor aponta princípios operacionais defensivos e ofensivos que regem, também, a todos os JEC, e que podem ser transferidos de uma modalidade para outra (conceito chamado pelo autor de tranfert), sendo eles:

Defesa:

- Proteger o alvo;

- Impedir a progressão do adversário;

- Recuperar a posse de bola. 
Ataque:

- Conservar a posse de bola;

- Progredir em direção ao alvo;

- Finalizar e marcar pontos

Bayer nos traz, ainda, o conceito de regras de ação, que seriam as estratégias que os jogadores, agora dentro de cada modalidade - tais como estabelecer linhas de passe e ocupar espaços vazios no ataque ou distribuir-se na quadra de defesa; assim, é a partir das regras de ação que as modalidades esportivas coletivas passam a diferenciar-se e não há ainda necessidade de refinamento dos gestos técnicos, mas sim que o jogador consiga analisar o jogo e tenha conhecimentos técnico-táticos suficientes para resolver os problemas do jogo.

Tendo em vista tais problemas a serem resolvidos pelos praticantes de JEC, Garganta (1995) nos apresenta a idéia de que existem dois traços tidos como fundamentais dentro da identidade e importância JDC: a cooperação e a inteligência. Quanto à inteligência, Garganta (1995) a definiu como "a capacidade de adaptação a novas situações em que o jogo nos coloca, isto é, capacidade de interpretar e operar adequadamente aos diversos problemas e situações que ocorrem durante o jogo"; de forma ampliada, Gardner (2000, p. 87) a definiu como "um potencial biopsicológico para processar informações que pode ser ativado num cenário cultural para solucionar problemas ou criar produtos que sejam valorizados em uma cultura". Desta forma, observamos que a inteligência está relacionada com a resolução de problemas em um determinado contexto, estando nos JEC bastante ligada à capacidade de interagir, individualmente ou em grupo, com a imprevisibilidade do jogo.

Destacando a resolução de problemas em grupo, Garganta ressalta a cooperação, destacando o ambiente dos JEC como muito favorável para sua manifestação. Freire (1998, p. 108) afirmou que "quando uma ação é melhor realizada por um grupo que por uma única pessoa, ela é uma ação cooperativa" e reforça a afirmativa de Garganta, ao tratar o esporte como "o jogo de quem é capaz de cooperar", considerando a cooperação definitiva no esporte.

Assim, tendo em vista a grandeza do fenômeno, cabe a nós, enquanto pedagogos do esporte, quando no trato do conteúdo JEC, organizar, sistematizar, planificar e aplicar os conhecimentos inerentes a este conteúdo de forma a otimizar sua compreensão por parte de nosso alunos. Desta forma, para a 
aprendizagem dos fundamentos presentes nos JEC, não nos parece adequada a ênfase na sua prática descontextualizada do jogo, ou seja, “o fazer desvinculado das razões de fazer” (GARGANTA, 1995).

O pedagogo do esporte, a partir destas alterações, será capaz de criar e modificar jogos de forma que estes se tornem possíveis para a compreensão dos princípios operacionais, sendo o aluno capaz de identificar problemas, analisar possibilidades de resolução e utilizar aquela que considerar a mais adequada em cada situação, aprendendo a interagir com a imprevisibilidade do jogo. Indo além da proposição de jogos, o pedagogo pode construí-los juntamente com os alunos, o que certamente será mais significativo para eles, que se sentirão co-responsáveis pela aula.

Desta forma, faz-se necessário adentrarmos a uma breve discussão acerca dos métodos de ensino em JEC.

\section{O MÉTODO}

As primeiras tentativas de sistematização de métodos para ensino de modalidades esportivas coletivas se deram por volta da década de 1960 e foram inspirados nos métodos já estruturados de modalidades esportivas individuais, sobretudo do atletismo. Tais propostas provinham de uma visão fragmentada do processo de ensino do esporte: se no atletismo cada parte do movimento da corrida de um atleta era ensinado separadamente, no esporte coletivo passou-se a ensinar e treinar cada fundamento do jogo de forma isolada, considerando que a partir das partes o aluno ou atleta aprenderia ou refinaria o todo.

Entretanto, observou-se que o fato de um jogador saber executar os movimentos e fundamentos do jogo de forma isolada não garantia ao mesmo condições de responder aos problemas apresentados pelo jogo, sobretudo aqueles de ordem tática, que permeiam todas as ações do jogo, inclusive as técnicas. Desta forma, a partir do final da década 1970 e início da década de 1980, surgem autores como Bayer (1976) na França, Bento, Garganta (1993) em Portugal, os autores do Teaching Game for Understanding (década de 1990) nos Estados Unidos e Thorpe, na Inglaterra, que propõem novos olhares sobre o processo de ensino e aprendizagem dos jogos esportivos coletivos, como estudamos anteriormente, que acarretaram em novos métodos de ensino dos JEC.

Nos remetendo a Dietrich et al. (1984), existem dois princípios relativamente resistentes e expressivos na metodologia de jogos, e que embasam tanto os métodos provenientes da década de 60 como aqueles que surgem a partir da década de 70, sendo eles: o analítico-sintético e o global-funcional. 
De acordo com o mesmo autor:

o princípio analítico-sintético se caracteriza por apresentar cursos de exercícios ou, esporadicamente, jogos, os quais partem de elementos especiais (técnicos, táticos ou condicionais dos jogos), reunindo-os, pouco a pouco em conexões maiores (síntese), recolhendo, posteriormente, as parte em conjuntos lógicos. (DIETRICH et al. 1984, p. 32)

Uma aula a partir do princípio analítico seria dividida em aquecimento, exercícios para a aprendizagem da técnica e jogo, tendo como princípios metodológicos, de acordo com Greco (1998):

- do conhecido ao desconhecido - das partes ao todo;

- do fácil para o difícil - diminuição da ajuda;

- do simples para o complexo - aproximação gradativa;

- divisão do movimento em fases funcionais.

O princípio global-funcional, por sua vez, baseia-se em jogos de menor complexidade que o formal, de caráter lúdico e adequados à faixa etária do iniciante e que envolvam técnica, tática e regras. Dietrich et al. (1984, p. 32), define:

o método global se caracteriza pela criação de cursos de jogos, que partem da simplificação dos jogos esportivos formais (basquetebol, handebol, futsal, etc.) de acordo com a idade, e, através de um aumento de dificuldades na apresentação dos jogos, em direção ao jogo final.

Entendemos que o método, no processo de iniciação, deva permitir ao aluno criar conceitos acerca dos JEC que possam ser transferidos para sua diversidade de práticas possíveis e até outros campos de sua vida; o aluno deve ser estimulado a compreender a lógica que permeia o jogo, de modo que não seja restringida ou limitada sua capacidade de assimilação e associação. Dessa forma, as atividades propostas pelo professor devem compor o contexto dos jogos; cabe ao agente pedagógico, através da metodologia de sua escolha, situar o aluno e torná-lo capaz de desenvolver novas habilidades por meio do jogo e não apenas repetir exaustivamente técnicas, mesmo porque nem sempre o praticante consegue transferi-las para o jogo.

Assim, observamos que o princípio analítico enfatiza a prática de tarefas motoras, através de exercícios de valor absoluto e previsíveis, sendo importantes para o desenvolvimento de habilidades básicas e de intimidade da criança com a bola. Em contrapartida, não acrescenta à criança habilidade em resolver os desafios propostos pelo jogo, o que é contemplado no princípio global-funcional, que propõe 
ênfase no jogo, oferece problemas imprevisíveis e de valor relativo a serem solucionados por quem joga; no entanto, o contato do aluno com a bola, neste princípio, tende a ser menor.

Desta forma, a partir da analise estrutural dos jogos esportivos coletivos, retomando as seis características propostas por Bayer, assim como uma análise dos objetivos destes jogos, propomos para a iniciação esportiva em modalidades coletivas a ênfase no jogo, englobando os aspectos citados por Bayer através de alterações nas regras de jogos de equipe já conhecidos e a criação de outros que apresentem os mesmos princípios operacionais. Para tal, sugerimos alguns elementos que nos dão a possibilidade de alterar ou construir jogos, a fim de potencializarmos o aprendizado do esporte coletivo a partir da compreensão do ato de jogar, e não apenas da repetição de técnicas, sendo eles:

- Regras;

- Espaço;

- Número de participantes;

- Tipo e número de bolas ou outros objetos;

- Tipo, número e posicionamento dos alvos;

- Partes do corpo com as quais são permitidas o contato com a bola ou outros objetos;

A partir das teorias abordadas, apresentamos a seguir a proposta de iniciação esportiva diversificada com foco nos JEC - aplicada no Tênis Clube de Campinas e que teve como predominância atividades propostas a partir do princípio global-funcional, tendo foco no jogo, tendo em vista que este permite maiores possibilidades do aluno em defrontar-se com situações onde a inteligência e a cooperação sejam mais requisitadas em situações de imprevisibilidade.

\section{BOLA AO ALTO: APLICANDO AS TEORIAS EM UM CLUBE PRIVADO NA CIDADE DE CAMPINAS/SP}

As teorias sobre JEC supracitadas nos levaram a elaboração de uma proposta de iniciação esportiva, aplicada em um clube privado na cidade de Campinas, cujo objetivo foi o de promover a iniciação com a diversificação de modalidades, tendo o foco nos Jogos Esportivos Coletivos (JEC), a partir das teorias propostas por Bayer (1994), Garganta (1995), Graça (1995), Paes (1996), Balbino (2001) e Galatti (2002). A proposta foi aplicada no Tênis Clube de Campinas (TCC) entre junho de 2004 e julho de 2005 
com cerca de 25 crianças entre 4 e 11 anos, em 3 diferentes turmas, todas compostas por meninos e meninas - a aula era aberta para crianças até 12 anos, entretanto não houve procura nesta faixa.

A partir das seis características comuns aos JEC propostos por Bayer (1994) - um objeto esférico; um espaço demarcado de jogo; um alvo a ser atacado ou defendido; os integrantes de uma equipe; adversários que devem ser vencidos; regras do jogo a serem respeitadas - , o trabalho com JEC na Escola de Esportes do TCC iniciou-se com a apresentação dos princípios operacionais de defesa e ataque através de jogos com poucas regras e nos quais ações individuais aconteciam com freqüência semelhante às coletivas. Assim, na defesa era importante que a criança reconhecesse a importância de proteger o alvo impedir a progressão do adversário e recuperar a posse de bola, através de uma ação individual ou coletiva. No ataque, estimulava-se a conservação da posse de bola, a progredir em direção ao alvo e a finalizar para marcar pontos, também sendo reforçada no discurso do professor a importância da ação coletiva em um jogo de equipe, ainda que muitas das opções tanto ofensivas como defensivas dos alunos fossem individuais, até pelas características da faixa etária. Este foco foi mantido com crianças entre 4 até cerca de 7 anos de idade, sendo agregadas vivências de outras modalidades esportivas de forma paralela, tais quais: tênis, atletismo, ginástica artística, ginástica ritma, boliche, esgrima, lutas e esportes paraolímpicos. As crianças entre 4 e 7 anos tinham duas aulas semanais com uma hora de duração cada, sendo que todas freqüentavam a escola e algumas praticavam ainda natação, futebol, tênis ou ballet no mesmo clube.

As crianças entre 7 ou 8 anos até os 11 anos também participavam do momento da aula destinado às crianças mais novas, entretanto, tinham uma hora a mais de aula por encontro, onde havia um aprofundamento nas teorias dos JEC. Assim, elas tinham duas aulas semanais de duas horas de duração cada; além do convívio com o esporte e outros elementos da cultura corporal na escola, todas as crianças desta faixa etária participavam de outras aulas de iniciação esportiva oferecidas pelo clube, em modalidades específicas diversas.

Com esta turma, que já apresentava uma experiência em jogos coletivos e atividades em equipe especialmente vivenciados na escola, foi possível avançarmos na prática da teoria proposta por Bayer, passando das características comuns e dos princípios operacionais e avançando para as regras de ação, que são a tipificação de esporte, necessárias para a realização dos princípios operacionais, colocados 
como formas gerais de resolução de problemas individuais ou coletivos de cada jogo ou modalidade esportiva. Assim, a compreensão da tática em cada jogo ou modalidade proposta era enfatizada, sendo o professor um mediador das descobertas táticas dos alunos, assim como das discussões acerca do sucesso ou insucesso de uma determinada tática escolhida por uma equipe em um jogo específico.

Foi considerada também, ao longo de todo o processo, a característica de imprevisibilidade dos JEC, o que justifica a ênfase em jogos e menor recorrência de exercícios ao longo das aulas; com igual importância, os estímulos à inteligência e a cooperação foram priorizados, uma vez que corroboramos com Garganta (1995) quando o autor considera estes dois traços fundamentais aos jogadores de JEC.

Com a continuidade dos alunos no projeto, a proposta era de que, posteriormente, os mesmos optassem por uma modalidade na qual iniciariam o processo de especialização. Embora não tenham sido elaborados métodos de avaliação do nível de compreensão dos jogos apresentados pelas crianças ao longo do processo, observou-se que as mesmas passaram a apresentar formas táticas mais elaboradas e com predominância de ações coletivas. Apesar dos autores não atuarem mais neste projeto, a "Escola de Esportes" do Tênis Clube de Campinas continua em atividade, de forma paralela ao oferecimento da iniciação esportiva em modalidades específicas.

\section{CONSIDERAÇÕES FINAIS}

O presente artigo propôs-se a apresentar uma possibilidade de iniciação esportiva diversificada, ou seja, que não tenha como objetivo a aprendizagem de uma única modalidade, mas sim que o aluno conheça o esporte em sua diversidade de práticas. A partir do estudo das teorias relacionadas aos jogos esportivos coletivos (JEC), em especial aquelas propostas por Bayer e Garganta, jogos e esportes coletivos tornaram-se o enfoque das práticas, embora outras vivências tenham sido oferecidas.

Assim, apresentamos aqui a aplicação destas idéias no Tênis Clube de Campinas, um clube privado no interior de São Paulo, onde conseguimos aliar esta nova proposta àquela já tradicional da iniciação esportiva em modalidades específicas. Não que este segundo modelo seja indevido, ao contrário, também deve ser oferecido, em especial quando se busca ensinar além do esporte, através do esporte, propondo-se práticas diversificadas dentro de uma especialidade esportiva.

A partir da riqueza de conteúdos práticos que pudemos sistematizar a partir das teorias européias para uma prática esportiva diversificada na infância em um clube brasileiro, sugerimos que este modelo 
global, universal ou diversificado aqui apresentado pode levar crianças a uma compreensão mais ampla acerca do esporte, suas manifestações, modalidades e possibilidades de práticas, levando-as a construção

da noção de tática e de coletividade, estabelecendo relações entre o esporte e a vida e apontando para uma real possibilidade de intervenção prática no esporte a partir de teorias estruturadas em diversos pontos do globo e adequadas para a realidade de cada contexto onde o esporte se manifesta no Brasil, contribuindo para a diminuição entre as tensões entre o global e o local na pedagogia do esporte.

\section{REFERÊNCIAS}

BALBINO, H. F. Jogos desportivos coletivos e os estímulos das inteligências múltiplas: bases para uma proposta em pedagogia do esporte. 2001. 142f. Dissertação (Mestrado em Educação Física) - Faculdade de Educação Física, Universidade Estadual de Campinas, Campinas, 2001.

BALBINO, H. F.; GALATTI, L. R.; PAES, R. R. Pedagogia do esporte: considerações pedagógicas e metodológicas no processo de ensino-aprendizagem do basquetebol. In: PAES, R. R.; BALBINO, H. F. Pedagogia do esporte: contextos e perspectivas. Rio de Janeiro: Guanabara Koogan, 2005.

BETTI, M. Cultura corporal e cultura esportiva. Revista Paulista de Educação. Física, São Paulo, v. 7, n. 2, p. 44 - 51, 1993.

CAGIGAL, J. M. Oh deporte! anatomia de um gigante. Valladolid: Miñon, 1981.

DIETRICH, K.; DURRWACHTER, G.; SCHALLER, H. J. Os grandes jogos: metodologia e prática. Rio de Janeiro: Ao Livro Técnico, 1984.

FREIRE, J. B. Esporte educacional. In: CONGRESSO LATINO AMERICANO DE EDUCAÇÃO MOTORA. 1., CONGRESSO BRASILEIRO DE EDUCAÇÃO MOTORA 2., Foz do Iguaçu, 1998. Anais..., 1998, p. 106-108.

GALATTI, L. R. Pedagogia do Esporte: discutindo o processo de ensino-aprendizagem na modalidade basquetebol. 2002. 98f. Monografia (Bacharelado em Educação Física) - Faculdade de Educação Física, Universidade Estadual de Campinas, Campinas, 2002.

GALATTI, L. R.; PAES, R. R. Fundamentos da pedagogia do esporte no cenário escolar. Movimento Percepção, Espírito Santo do Pinhal, v. 6, n. 9, p. 16-25. 2006. Disponível em: $<$ http://www.unipinhal.edu.br/movimentopercepcao> Acesso em 08 ago. 2006. 
GARDNER, H. Inteligências: um conceito reformulado. Rio de Janeiro: Objetiva, 2000.

GARGANTA, J. Para uma teoria dos jogos desportivos coletivos. In: GRAÇA, A.; OLIVEIRA, J. (Eds.). O ensino dos jogos desportivos coletivos. 2. ed. Lisboa: Universidade do Porto, 1995. p. 11-25.

GRAÇA, A. Os comos e os quandos no ensino de jogos. In: GRAÇA, A.; OLIVEIRA, J. (Ed.). O ensino dos jogos desportivos coletivos. 2. ed. Lisboa: Universidade do Porto, 1995. p. 27-34.

GRECO, J. P.; BENDA, R. N. (Org.). Iniciação desportiva universal. Belo Horizonte: Ed. Da UFMG, 1998.

HUIZINGA, J. Homo ludens: o jogo como elemento da cultura. 4. ed. São Paulo: Perspectiva, 1993.

MONTAGNER, P. C. Esporte de competição X educação?: o caso do basquetebol. 1993. $148 \mathrm{f}$. Dissertação (Mestrado em Educação Física) - Faculdade de Educação Física, Universidade Metodista de Piracicaba, Piracicaba, 1993.

PAES, R. R. Aprendizagem e competição precoce: o caso do basquetebol. 3. ed. Campinas: Ed. da Unicamp, 1997.

. Educação física escolar: o esporte como conteúdo pedagógico do ensino fundamental. Canoas: Ed. da Ulbra, 2001.

. Esporte educacional In: CONGRESSO LATINO AMERICANO DE EDUCAÇÃO MOTORA. 1., CONGRESSO BRASILEIRO DE EDUCAÇÃO MOTORA 2., 1998, Foz do Iguaçu. Anais... 1998, p. 109-114.

PAES, R. R.; BALBINO, H. F. Pedagogia do esporte contextos e perspectivas. Rio de Janeiro: Guanabara Koogan, 2005.

TEODORESCU, L. Problemas de teoria e metodologia nos jogos desportivos. Lisboa: Livros Horizonte, 1984.

TUBINO, M. J. G. Teoria geral do esporte. São Paulo: IBRASA, 1987. 


\section{Larissa Rafaela Galatti}

Faculdade de Educação Física-IASP/FEF-UNICAMP

\section{Roberto Rodrigues Paes}

Faculdade de Educação Física-UNICAMP

\section{Referência do artigo:}

\section{ABNT}

GALATTI, L. R., PAES R. R. Pedagogia do esporte e a aplicação das teorias acerca dos jogos esportivos coletivos em escolas de esportes: o caso de um clube privado de Campinas-SP. Conexões, v.5, n. 2, p. 31-44, 2007.

\section{APA}

Galatti, L. R., \& Paes R. R. (2007). Pedagogia do esporte e a aplicação das teorias acerca dos jogos esportivos coletivos em escolas de esportes: o caso de um clube privado de Campinas-SP. Conexões, $5(2), 31-44$.

\section{VANCOUVER}

Galatti LR, Paes RR. Pedagogia do esporte e a aplicação das teorias acerca dos jogos esportivos coletivos em escolas de esportes: o caso de um clube privado de Campinas-SP. Conexões, 2007, 5(2): 31-44. 